\title{
Copper oxide-graphene oxide nanocomposite: efficient catalyst for hydrogenation of nitroaromatics in water
}

\author{
Kaiqiang Zhang 1,2, Jun Min Suh', Tae Hyung Lee ${ }^{1}$, Joo Hwan Cha ${ }^{3}$, Ji-Won Choi ${ }^{2}$, Ho Won Jang ${ }^{1 *}$, \\ Rajender S. Varma ${ }^{4^{*}}$ and Mohammadreza Shokouhimehr ${ }^{1 *}$
}

\begin{abstract}
A low-cost nanocomposite catalyst containing copper oxide (CuO) nanoparticles (NPs) on graphene oxide (GO) was fabricated by a facile hydrothermal self-assembly process. The segregated CuO NPs and GO exhibited negligible cataIytic activities for the reduction of nitroaromatics. However, their hybrid composite accomplished facile reduction with high conversions for several substituted nitroaromatics in aqueous $\mathrm{NaBH}_{4}$ solution; synergetic coupling effect of CuO NPs with GO in the nanocomposite catalyst provided excellent catalytic activity. The nanocomposite catalyst could be separated from the reaction mixture and recycled consecutively.
\end{abstract}

Keywords: Copper oxide, Graphene oxide, Hydrothermal, Hydrogenation, Synergistic effect

\section{Introduction}

Catalysts play deterministic roles in the hydrogenation of nitroaromatics to aminoaromatics [1-3]. The development of highly active catalysts has attracted remarkable attention for the next-generation green, cost-effective and efficient reduction processes. In particular, the engineered metal nanoparticles (NPs) and nanocomposites have significantly improved the efficiency of catalytic systems. Consequently, various approaches have been utilized to fabricate the inexpensive nanostructured catalysts [4-7]. Varma et al. has emphasized the importance of the greener methods to synthesize nanocomposite catalysts [8]. Virkutyte et al. has reviewed various approaches for the fabrication of stable, environmentally benign, and active metal NPs for catalytic applications [9]. A summary of

\footnotetext{
*Correspondence: hwjang@snu.ac.kr; varma.rajender@epa.gov; mrsh2@snu.ac.kr

${ }^{1}$ Department of Materials Science and Engineering, Research Institute of Advanced Materials, Seoul National University, Seoul 08826, Republic of Korea

${ }^{4}$ Regional Centre of Advanced Technologies and Materials, Faculty of Science, Palacky University in Olomouc, Šlechtitelů 27,783

71 Olomouc, Czech Republic

Full list of author information is available at the end of the article
}

nanocatalysts utilized for the environmentally friendly reduction of nitroaromatics has also been reviewed by Zhang and colleagues, emphasizing the advantages of the introduced heterogeneous catalysts [10]. However, several drawbacks of the present catalysts need to be circumvented namely enhancing the specific surface area, long-term stability, production cost diminution, and ecological concerns pertaining to their industrial applications [11-14]. To fabricate such catalysts possessing the aforementioned competencies, various nanostructured catalysts have been designed and synthesized [15-17]; metal NPs have been stabilized on variable robust nanostructures, producing active nanocomposite catalysts for reduction of nitroaromatics [18-20]. These heterogeneous catalysts generally comprise precious metal nanocatalysts e.g. Pd, Pt, Rh, $\mathrm{Ru}$ etc. to achieve efficient hydrogenation of nitroaromatics [20-22]. However, they are not broadly utilized in the chemical industries due to their high costs which is critical issue from the economical viewpoint [23]. In comparison, earth abundant elements e.g. $\mathrm{Cu}, \mathrm{Co}, \mathrm{Fe}$, $\mathrm{Mn}$, and $\mathrm{Ni}$ are inexpensive and may serve as appropriate catalysts for several catalytic transformations, but with low catalytic activity [24-26]. The nano-sized 
counterparts of these catalysts also get aggregated quickly in the reaction media due to their high surfaceto-volume ratio, limiting their efficiency and reusability $[27,28]$. Consequently, engineering hybrid catalysts consist of nanocatalysts integrated susceptible supports is necessary to promote their activities. The nanocomposite catalysts often present improved catalytic properties by exhibiting synergetic effects between the supports and nanocatalysts [29-31].

Graphene has been extensively employed as a stable and excellent nanocatalysts support for synthesizing efficient heterogeneous catalysts [32, 33]; its exceptional conductivity can facilitate the electron transfer during the transformations [34]. Consequently, metal nanocatalysts supported on the graphene may potentially promote the reductants' electrons donation in the reaction media enhancing the reduction efficiency. Indeed, the synergetic effect between less-reactive nanocatalysts and graphene leads to highly active hybrid nanocomposite catalysts [35].

Motivated by the aforementioned advantages, we synthesized an efficient nanocomposite catalyst consist of graphene oxide (GO) supported copper oxide $\mathrm{NPs}(\mathrm{CuO}-\mathrm{GO})$ via a facile hydrothermal self-assembly process for the reduction of nitroaromatics. The $\mathrm{CuO}-$ GO nanocomposite catalyst exhibited high yields for the reduction of various nitroaromatics using aqueous sodium borohydride $\left(\mathrm{NaBH}_{4}\right)$ at room temperature.

\section{Experimental}

\subsection{Materials and characterization}

Water was deionized by a Nano Pure System (Barnsted). The reagents used in this research were purchased from SigmaAldrich, Samchun, and Daejung and used without any further purification. X-ray photoelectron spectroscopy (XPS) was performed using an $\mathrm{Al} \mathrm{K \alpha}$ source (Sigma probe, VG Scientifics) to characterize the surface chemical composition. The nanostructure of the prepared $\mathrm{CuO}-\mathrm{GO}$ nanocomposite catalyst was studied using a high resolution X-ray diffraction (XRD, D8-Advance), a transmission electron microscope (TEM, JEOL JEM3010) equipped with an energy-dispersive X-ray spectroscopy (EDX) detector, a scanning TEM (STEM, JEOL JEM-2100F), a thermal gravimetric analysis (TGA, simultaneous DTA/TGA analyzer), Raman technology (LabRAM HV Evolution), and a Fourier TransformInfrared Radiation spectroscopy (FT-IR, Nicolet iS50). Gas chromatography-mass spectrometry (GC-MS, Agilent Technologies 7693 Autosampler and 5977A Mass selective detector) was employed to monitor the conversion ratio of the nitroaromatics to aminoaromatics.

\subsection{Preparation of GO}

Graphene oxide was synthesized from graphite using the modified hummer's approach [36]. Commercial graphite powder $(10 \mathrm{~g})$ was added into $230 \mathrm{~mL}$ concentrated $\mathrm{H}_{2} \mathrm{SO}_{4}$ and cooled to $\sim 20{ }^{\circ} \mathrm{C}$ with a circulator. $300 \mathrm{~g}$ potassium permanganate was added while stirring. Then, the temperature of the reaction was adjusted to $40{ }^{\circ} \mathrm{C}$ and the mixture was stirred for $1 \mathrm{~h}$. Water $(500 \mathrm{~mL})$ was added to the mixture and the temperature was increased to $100{ }^{\circ} \mathrm{C} .2 .5 \mathrm{~mL} \mathrm{H}_{2} \mathrm{O}_{2}$ (30 wt\%) was slowly added to the mixture. For purification, the suspension was washed with $\mathrm{HCl}$ solution $(200 \mathrm{~mL})$ using a filter and a funnel. The suspension was washed with water several times until the filtrate became neutral.

\subsection{Preparation of CuO-GO nanocomposite catalyst}

$\mathrm{CuO}-\mathrm{GO}$ nanocomposite catalyst was successfully synthesized using a facile hydrothermal self-assembly process by modifying a previously reported method [36]. $\mathrm{CuCl}_{2}(2 \mathrm{mmol})$ was dissolved in deionized water and mixed with the as-synthesized $\mathrm{GO}$ solution $(15 \mathrm{~mL})$ and transferred into a clean Teflon-lined container. Thereafter, the Teflon-lined container was filled $(70 \%$ in volume) with deionized water, placed in an autoclave and tightly sealed, followed by heating up to $150{ }^{\circ} \mathrm{C}$ for $12 \mathrm{~h}$. After gradually cooling down, the product was washed with sufficient deionized water and filtered for several times to remove the non- and/or poor-anchored copper oxide NPs on the GO.

\subsection{Catalytic reduction of nitroaromatics}

The reduction of nitroaromatics to aminoaromatics was carried out using $\mathrm{CuO}-\mathrm{GO}$ nanocomposite catalyst with aqueous $\mathrm{NaBH}_{4}$ as a reductant at room temperature. In a typical procedure, nanocomposite catalyst (50 mg) was dispersed in deionized $\mathrm{H}_{2} \mathrm{O}(30 \mathrm{~mL})$. Then, a nitroaromatics $(1 \mathrm{mmol}), \mathrm{NaBH}_{4}(1.2 \mathrm{mmol})$ and a small stirring bar were added into the reaction glass flask. The reaction mixture was stirred at room temperature for 30 min under air atmosphere. After completion of the reaction, the $\mathrm{CuO}-\mathrm{GO}$ nanostructured catalyst was separated using a centrifuge. The yields of the aminoaromatics products were measured using a GC-MS. For the reusability evaluation of the nanocomposite catalyst, the separated catalyst was washed with deionized water and dried in an oven for the following runs. The cycling performance was achieved by repeating the above reduction process. 


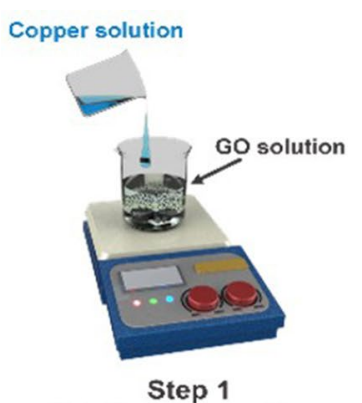

Solution preparation

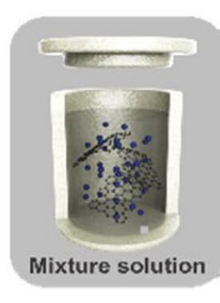

Hydrothermal self-assembly

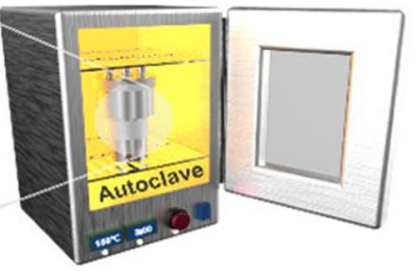

Step 2

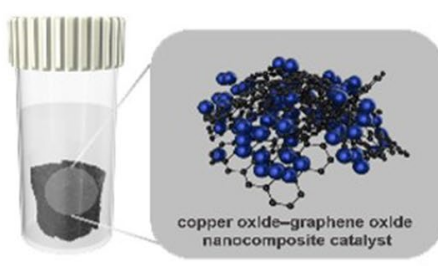

Step 3

Segregation

Fig. 1 Schematic illustration for the synthesis of the $\mathrm{CuO}-\mathrm{GO}$ nanocomposite catalyst
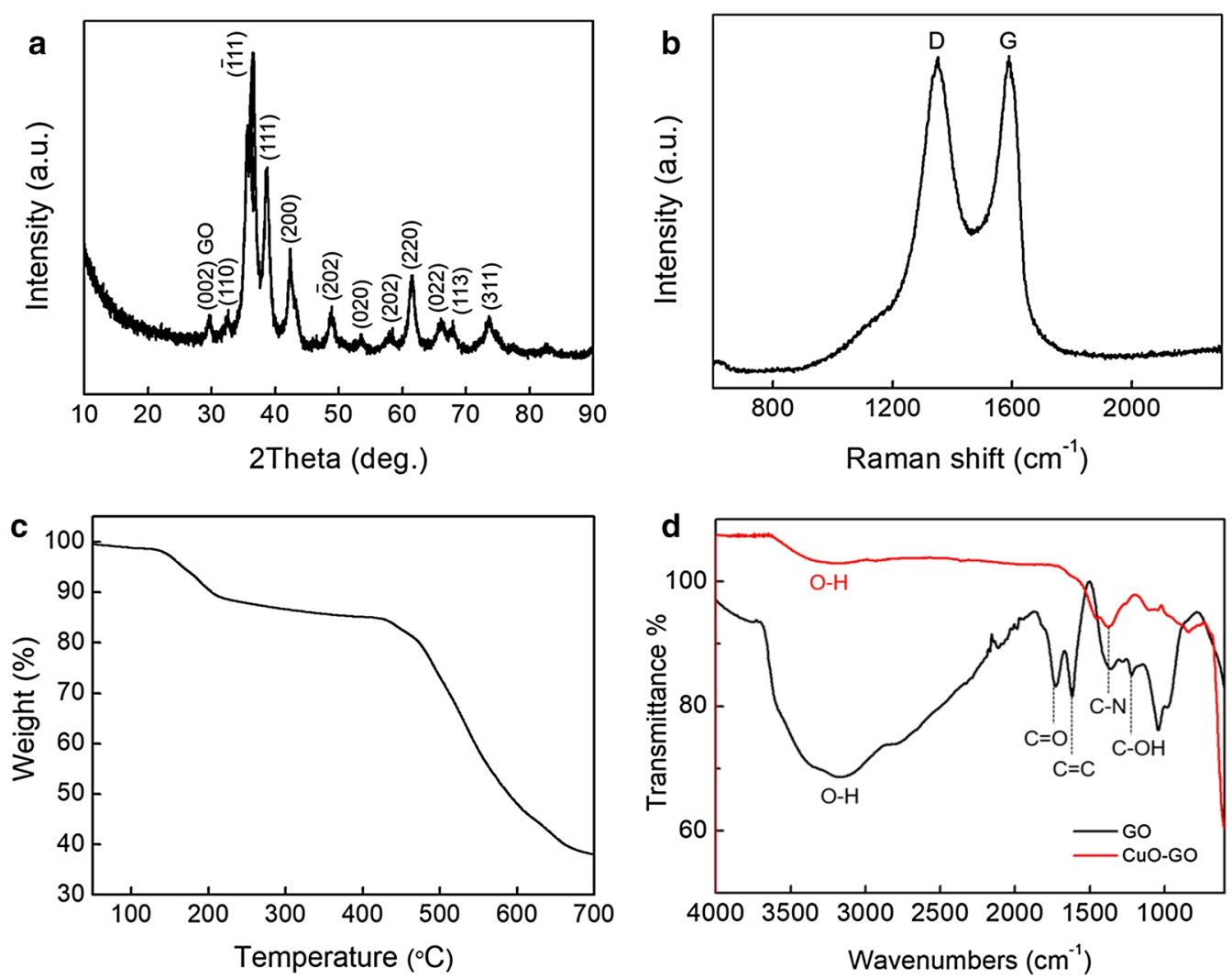

Fig. 2 a XRD diffraction pattern, b Raman spectrum, c TGA analysis, and d FT-IR spectrum of the CuO-GO nanocomposite catalyst

\section{Results and discussion}

Figure 1 depicts the overall synthetic procedure accomplished using a low-cost synthesis for $\mathrm{CuO}-\mathrm{GO}$ nanocomposite catalyst. The XRD peaks (Fig. 2a) of the nanocomposite catalyst display are well indexed with GO and CuO (JCPDS Card no. 89-2530). The composition of the catalyst was further characterized by Raman technology to verify the GO support (Fig. 2b). The G line (first-order scattering of the $E_{2 g}$ phonons of $\mathrm{sp}^{2}$ orbital) at $1580 \mathrm{~cm}^{-1}$ and D line ( $\mathrm{K}$-point phonons of $A_{1 g}$ symmetry) at $1350 \mathrm{~cm}^{-1}$ are clearly acquired for the nanocomposite catalyst as specific characteristics of graphene [37]. The thermal-stability of the catalyst was ascertained using TGA (Fig. 2c) under the nitrogen atmosphere with a temperature ramp of $10{ }^{\circ} \mathrm{C} \mathrm{min}{ }^{-1}$, demonstrating the presence of $\sim 15 \mathrm{wt} \%$ moisture 

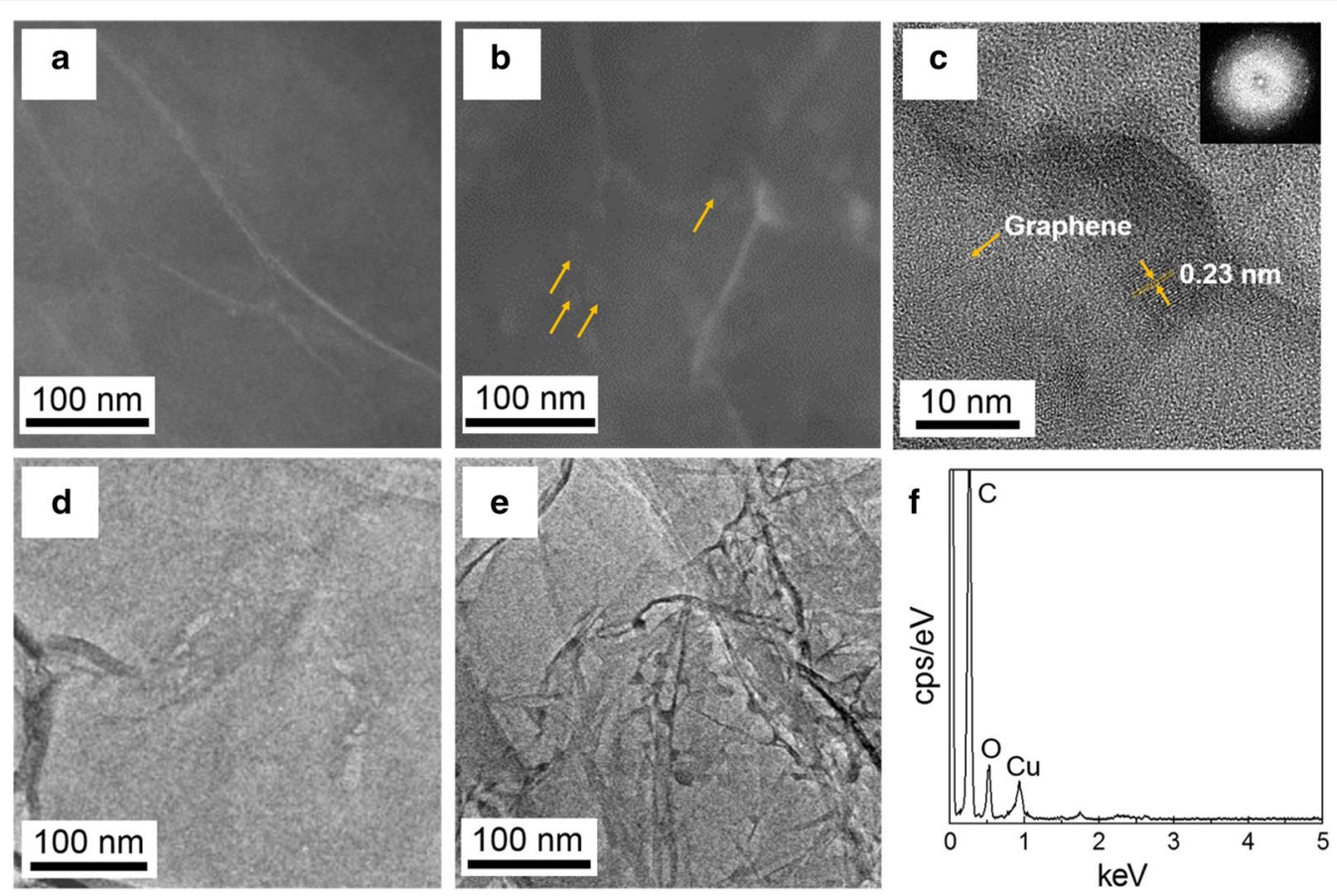

Fig. 3 a, d TEM and STEM images of GO. b, e TEM and STEM images of the CUO-GO nanocomposite catalyst. $\mathbf{c}$ HRTEM image of the CuO-GO nanocomposite catalyst. The inset shows the relevant FFT image. $\mathbf{f}$ EDX spectrum of the CuO-GO nanocomposite catalyst
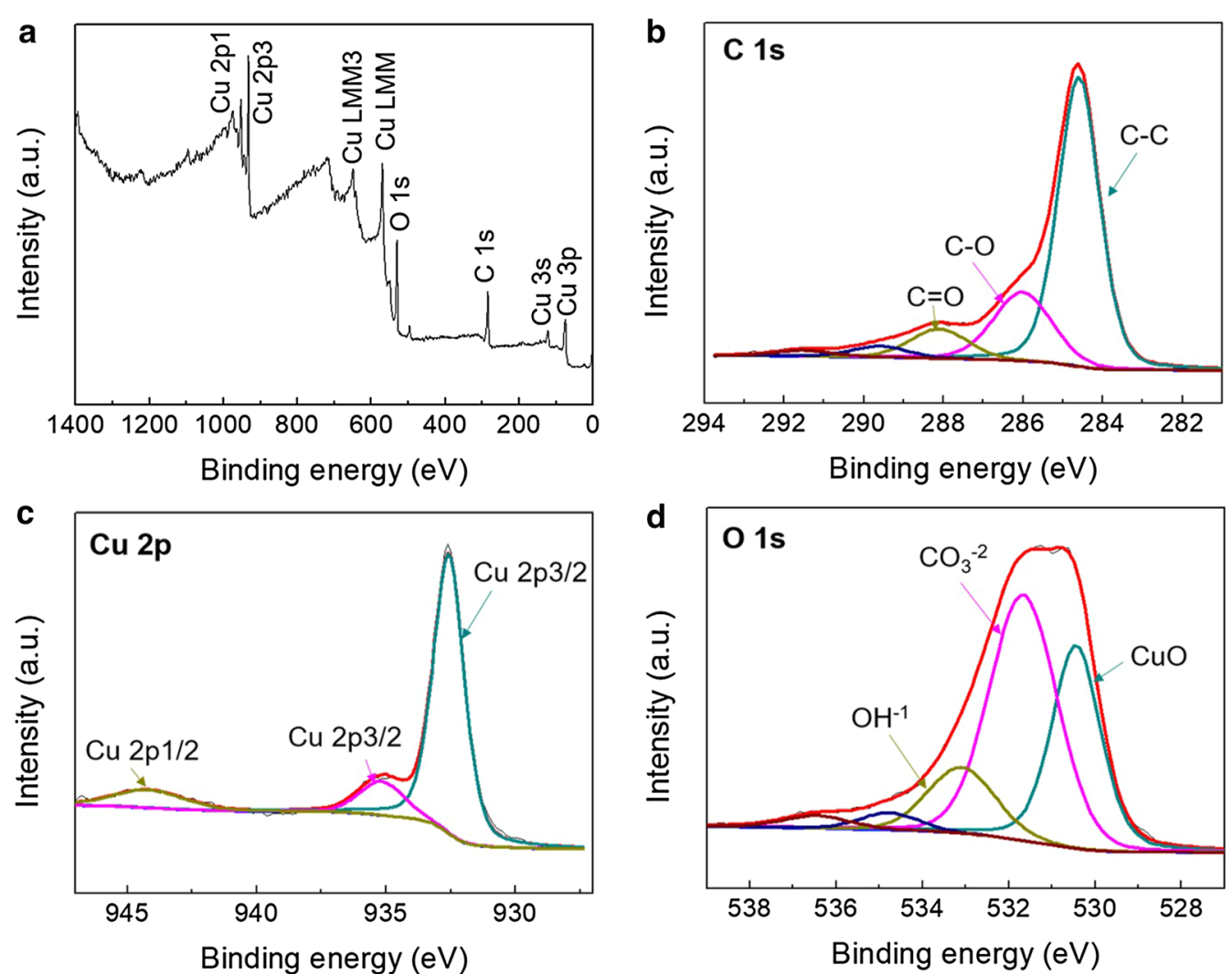

Fig. 4 XPS analysis a survey scan, b C 1s, c Cu 2p, and d O 1s for the CuO-GO nanocomposite catalyst 
according to the first weight decrease and $\sim 45 \mathrm{wt} \%$ graphene based on the second weight loss. Accordingly, weight percentage ratio of graphene to copper oxide species in the nanocomposite catalysts was found to be $\sim 1: 1$.

The composition of the nanocomposite catalyst was further confirmed by FT-IR (Fig. 2d). A strong peak at $3450 \mathrm{~cm}^{-1}(\mathrm{O}-\mathrm{H}$ stretching vibrations) in the case of GO indicates $\mathrm{H}_{2} \mathrm{O}$ residual compared with $\mathrm{CuO}-\mathrm{GO}$ nanocomposite catalyst even after sufficient drying. In addition, the characteristic bands of GO are clearly revealed at $1725 \mathrm{~cm}^{-1}$ for $\mathrm{C}=\mathrm{O}$ stretching vibrations and $1600 \mathrm{~cm}^{-1}$ for $\mathrm{C}=\mathrm{C}$ (skeletal vibrations of graphene). These peaks disappeared in the $\mathrm{CuO}-\mathrm{GO}$ nanocomposite catalyst verifying the reduction of $\mathrm{GO}$ during the hydrothermal process.

The STEM and TEM images (Fig. 3b, e) of the CuOGO heterogeneous nanocomposite catalyst clearly revealed a uniform distribution of copper oxide NPs in comparison with GO sheets (Fig. 3a, d) after the hydrothermal self-assembly process. The high resolution TEM and fast Fourier transform (FFT) images (Fig. 3c) of the nanocomposite catalyst further provided valuable evidences for the spatial homogeneously confined and crystalline copper oxide NPs immobilized on GO framework. The crystalline NPs with the size of $\sim 10 \mathrm{~nm}$ in diameter present nano-scale $\mathrm{CuO}$ grains with interplanar spacing of $0.23 \mathrm{~nm}$ on GO. The small size NPs expose high active sites on the surface, facilitating highly efficient hydrogenation. The EDX spectrum results determined the existence of $\mathrm{Cu}$ and $\mathrm{O}$ elements distribution on GO support (Fig. 3f).

The surface composition and existing elements on the nanocomposite catalyst were confirmed by XPS (Fig. 4). The survey spectrum (Fig. 4a) shows the surface binding situation, ascertaining the presence of $\mathrm{Cu}, \mathrm{O}$, and $\mathrm{C}$ elements in the nanocomposite catalyst (Fig. 4b-d). Carbon peaks are deconvoluted into three peaks, where the primary $\mathrm{C}-\mathrm{C}$ bond generated by $\mathrm{sp}^{2}$ orbital hybridization shown at $284.6 \mathrm{eV}$. The oxide graphene is further verified by the $\mathrm{C}-\mathrm{O}$ bond at $286.2 \mathrm{eV}$. $\mathrm{Cu}$ has binding energy of $944.3 \mathrm{eV}\left(\mathrm{Cu} 2 \mathrm{p}_{1 / 2}\right)$ and 935.8, $932.8 \mathrm{eV}(\mathrm{Cu}$ $2 \mathrm{p}_{3 / 2}$ ) with $\mathrm{O} 1 \mathrm{~s}$ possessing binding energy of $530.6 \mathrm{eV}$ thus demonstrating the existence of copper oxide in the nanocomposite catalyst. The other two peaks with binding energies of $533.2 \mathrm{eV}$ and $531.8 \mathrm{eV}$ can be ascribed to the absorption of water and oxygen molecules from environment. Others deconvoluted peaks with much lower intensities $(536.6 \mathrm{eV}$ and $535.8 \mathrm{eV})$ are the satellite peaks of C.

The catalytic activity of the nanocomposite catalyst was first examined in the reduction of 4-nitrobenzene with aqueous $\mathrm{NaBH}_{4}$ as a model reaction; high yield
Table 1 Heterogeneous reduction of substituted nitroaromatics catalyzed by CuO-GO nanocomposite catalyst in aqueous solution

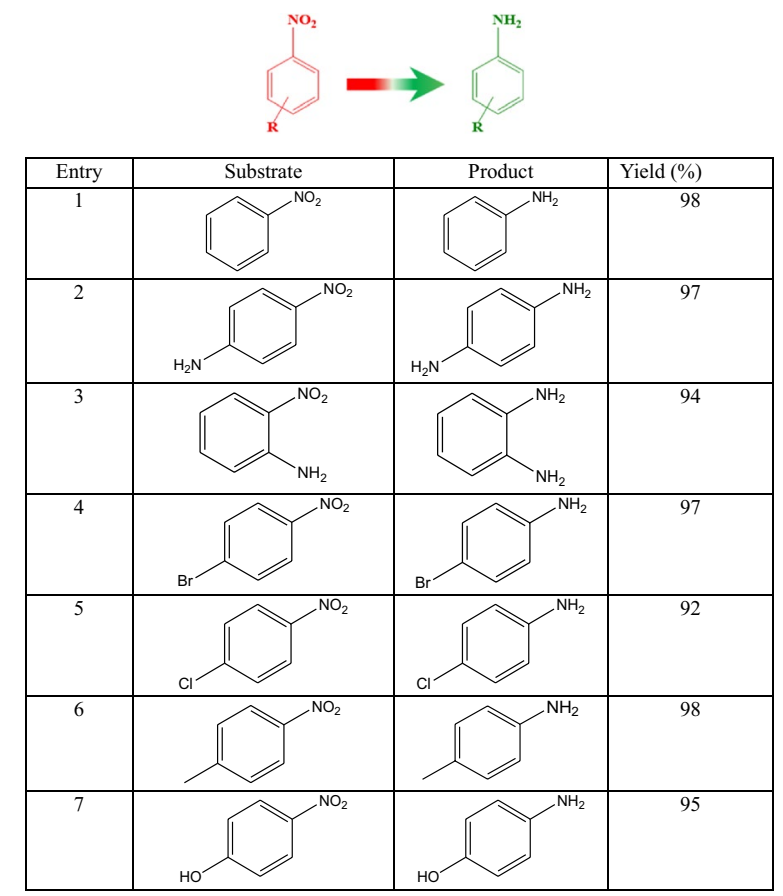

Reaction conditions: nitroaromatics ( $1 \mathrm{mmol}), \mathrm{NaBH}_{4}(1.2 \mathrm{mmol}), 30 \mathrm{~min}$, $\mathrm{CuO}-\mathrm{GO}$ nanocomposite catalyst $(50 \mathrm{mg})$, aqueous solution. The yields were determined by GC-MS

of conversion of 4-aminobenzene (98\%, Table 1) was achieved. Although the selective reduction of a nitro moiety in the nitroaromatic compounds comprising another reducible functional group is a difficult transformation, nanocomposite catalyst selectively reduced the nitro to the amino moiety (Table 1, entries 2-7), demonstrating the feasibility of the synthesized catalyst for broad catalytic reduction applications. The excellent catalytic activity of the catalyst can be ascribed by the synergetic effect between copper oxide NPs and graphene oxide [38]. To highlight the catalytic activity of the $\mathrm{CuO}-\mathrm{GO}$ nanocomposite catalyst in reduction of nitroaromatics, we compared the previously reported articles (Table 2) with the current catalyst. The $\mathrm{CuO}-$ GO nanocomposite catalyst showed less catalytic activity in comparison with other heterogeneous catalysts having noble-metals e.g. Pd, Pt etc. However, considering the low price of copper, a competitive catalytic activity was exhibited by the $\mathrm{CuO}-\mathrm{GO}$ nanocomposite catalyst. Furthermore, the reusability of heterogeneous catalysts is necessary for its pragmatic usages [39-45]. The CuO-GO nanocomposite catalyst was successfully reused for six consecutive cycles of the reduction of 4-nitrotoluene with a good yield of $85 \%$ (Fig. 5). 
Table 2 Catalytic comparison study of known heterogeneous catalysts in the reduction of nitrophenol

\begin{tabular}{llll}
\hline Entry & Catalyst & Reductant & Time (min) \\
\hline 1 & Graphene-Cu ${ }_{36} \mathrm{Ni}_{64}$ & $\mathrm{NH}_{3} \mathrm{BH}_{3}(3 \mathrm{mmol})$ & $30[37]$ \\
2 & $\mathrm{Cu}-\mathrm{Ni}$-AAPTMS@GO & $\mathrm{NaBH}_{4}(1.5 \mathrm{mmol})$ & $4[38]$ \\
3 & $\mathrm{Ru}_{50} \mathrm{Ni}_{50} / \mathrm{RGONCS}$ & $\mathrm{NH}_{3} \mathrm{BH}_{3}(2 \mathrm{mmol})$ & $4.5[39]$ \\
4 & $\mathrm{Pt} / \mathrm{RGO}$ & $\mathrm{H}_{2}(1 \mathrm{MPa})$ & $120[40]$ \\
5 & $\left(\mathrm{CO}_{6}\right) \mathrm{Ag}_{0.1} \mathrm{Pd}_{0.9} / \mathrm{RGO}$ & $\mathrm{HCONH}_{4}(4 \mathrm{mmol})$ & $20[41]$ \\
6 & $\mathrm{Pd} / \mathrm{GO}$ & $\mathrm{NaBH}_{4}(1.2 \mathrm{mmol})$ & $10[42]$ \\
7 & $\mathrm{MRN}-\mathrm{Pd}$ & $\mathrm{NaBH}_{4}(1.2 \mathrm{mmol})$ & $45[43]$ \\
8 & $\mathrm{CuSO} / \mathrm{GO}$ & $\mathrm{NaBH}_{4}(1.2 \mathrm{mmol})$ & $30[$ This work] \\
\hline
\end{tabular}

\section{Conclusions}

Small copper oxide NPs $(\sim 10 \mathrm{~nm})$ formed nanocomposite with graphene oxide by a facile and cost-efficient hydrothermal self-assembly approach. Although GO and $\mathrm{CuO}$ NPs separately showed low catalytic activities in the reduction of nitroaromatics, their composite presented excellent reduction performance with high yield and selectivity for the conversion of various nitroaromatics bearing different functional groups, which can be described by the synergetic effect. In addition, the nanocomposite catalyst could be recycled for up to six uses. This system can be a promising heterogeneous catalyst for the future reduction of nitroaromatics premeditated in large scale wherein the low-cost and facile fabrication are demanded.

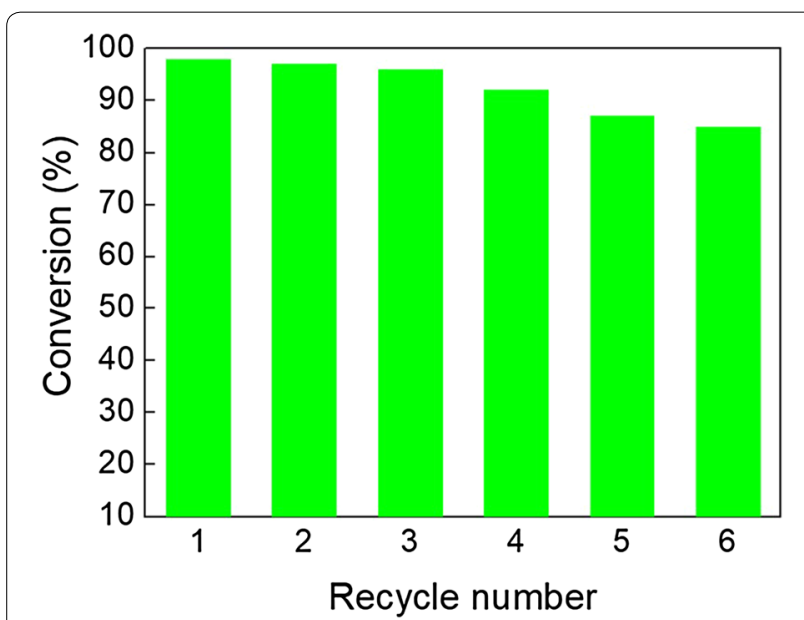

Fig. 5 Reuse of the CuO-GO nanocomposite catalyst in the heterogeneous reduction of 4-nitrotoluene. Reaction conditions: 4-nitrotoluene (1 mmol), $\mathrm{NaBH}_{4}(1.2 \mathrm{mmol})$, catalyst (50 mg), room temperature, aqueous solution, and $30 \mathrm{~min}$. The yields were determined by GC-MS
Authors' contributions

All authors contributed to the accomplishment of the project and writing of the manuscript. All authors read and approved the final manuscript.

\section{Author details \\ ${ }^{1}$ Department of Materials Science and Engineering, Research Institute of Advanced Materials, Seoul National University, Seoul 08826, Republic of Korea. ${ }^{2}$ Center for Electronic Materials, Korea Institute of Science and Tech- nology (KIST), Seoul 02792, Republic of Korea. ${ }^{3}$ Small \& Medium Enterprises Support Center, Korea Institute of Science and Technology (KIST), Seoul 02792 Republic of Korea. ${ }^{4}$ Regional Centre of Advanced Technologies and Materials, Faculty of Science, Palacky University in Olomouc, Šlechtitelů 27, 78371 Olo- mouc, Czech Republic}

\section{Competing interests}

The authors declare that they have no competing interests.

\section{Availability of data and materials}

The authors do not have other results to share as all data are shown in the present article.

\section{Consent for publication \\ Not applicable.}

\section{Ethics approval and consent to participate}

Not applicable.

\section{Funding}

The financial supports of the Future Material Discovery Program (2016M3D1A1027666), and the Basic Science Research Program

(2017R1A2B3009135) through the National Research Foundation of Korea are appreciated.

\section{Publisher's Note}

Springer Nature remains neutral with regard to jurisdictional claims in published maps and institutional affiliations.

Received: 20 December 2018 Accepted: 11 February 2019 Published online: 21 February 2019

\section{References}

1. T. Zeng, H.Y. Niu, Y.R. Ma, W.H. Li, Y.Q. Cai, Appl. Catal. B-Environ. 134, 26 (2013)

2. M. Shokouhimehr, J.E. Lee, S.I. Han, T. Hyeon, Chem. Commun. 49, 4779 (2013)

3. M. Shokouhimehr, T. Kim, S.W. Jun, K. Shin, Y. Jang, B.H. Kim, J. Kim, T. Hyeon, Appl. Catal. A Gen. 476, 133 (2014)

4. M.B. Gawande, V.D.B. Bonifácio, R. Luque, P.S. Branco, R.S. Varma, Chem. Soc. Rev. 42, 5522 (2013)

5. K.H. Choi, M. Shokouhimehr, Y.S. Kang, D.Y. Chung, Y.H. Chung, M. Ahn, Y.E. Sung, Bull. Korean Chem. Soc. 34, 1195 (2013)

6. V. Polshettiwar, R.S. Varma, Green Chem. 12, 743 (2010)

7. M. Shokouhimehr, M. Shahedi Asl, B. Mazinani, Res. Chem. Intermed. 44, 1617 (2018)

8. R.S. Varma, Curr. Opin. Chem. Eng. 1, 123 (2012)

9. J. Virkutyte, R.S. Varma, Chem. Sci. 2, 837 (2011)

10. K. Zhang, J.M. Suh, J.W. Choi, H.W. Jang, M. Shokouhimehr, R.S. Varma, ACS Omega 4, 483 (2019)

11. Y. Hu, K. Tao, C. Wu, C. Zhou, H. Yin, S. Zhou, J. Phys. Chem. C 117, 8974 (2013)

12. M. Shokouhimehr, J.H. Kim, Y.S. Lee, Synlett 04, 618 (2006)

13. J. Hagen, Industrial catalysis: a practical approach (Wiley-VCH, Hoboken, 2006)

14. M. Shokouhimehr, Catalysts 5, 534 (2015)

15. R.B. Nasir Baig, R.S. Varma, Green Chem. 15, 398 (2013)

16. O. Verho, K.P.J. Gustaffson, A. Nagendiran, C.W. Tai, J.E. Backvall, ChemCatChem 6, 3153 (2014)

17. Y.M. Lu, H.Z. Zhu, W.G. Li, B. Hu, S.H. Yu, J. Mater. Chem. A 1, 3783 (2013) 
18. K. Kuroda, T. Ishida, M. Haruta, J. Mol. Catal. A 298, 7 (2009)

19. Z. Dong, X. Le, X. Li, W. Zhang, C. Dong, J. Ma, Appl. Catal. B 158, 129 (2014)

20. Z. Dong, X. Le, C. Dong, W. Zhang, X. Li, J. Ma, Appl. Catal. B 162, 372 (2015)

21. A. Kim, S. Abdolhosseini, S.M. Rafiaei, M. Shokouhimehr, Energy Environ Focus 4, 18 (2015)

22. I. Lee, J.B. Joo, M. Shokouhimehr, Chin. J. Catal. 36, 1799 (2015)

23. S. He, H. Niu, T. Zeng, S. Wang, Y. Cai, ChemistrySelect 1, 2821 (2016)

24. M. Karthik, P. Suresh, ChemistrySelect 2, 6916 (2017)

25. Y.G. Wu, M. Wen, Q.S. Wu, H. Fang, J. Phys. Chem. C 118, 6307 (2014)

26. B. Tang, W.C. Song, E.C. Yang, X.J. Zhao, RSC Adv. 7, 1531 (2017)

27. N. Zhang, Y.J. Xu, Chem. Mater. 25, 1979 (2013)

28. R.G. Kadam, A.K. Rathi, R. Zboril, R.S. Varma, M.B. Gawande, R.V. Jayaram, ChemPlusChem 82, 467 (2015)

29. Z.S. Wu, S. Yang, Y. Sun, K. Parvez, X. Feng, K. Müllen, J. Am. Chem. Soc. 134, $9082(2012)$

30. Y. Liang, Y. Li, H. Wang, J. Zhou, J. Wang, T. Regier, H. Dai, Nat. Mater. 10 780 (2011)

31. J. Shi, Chem. Rev. 113, 2139 (2013)

32. S.I. El-Hout, S.M. El-Sheikh, H.M. Hassan, F.A. Harraz, I.A. Ibrahim, E.A. ElSharkawy, Appl. Catal. A Gen. 503, 176 (2015)

33. Y. Cheng, Y. Fan, Y. Pei, M. Qiao, Catal. Sci. Technol. 5, 3903 (2015)
34. B. Ma, Y. Wang, X. Tong, X. Guo, Z. Zheng, X. Guo, Catal. Sci. Technol. 7, 2805 (2017)

35. A. Goswami, A.K. Rathi, C. Aparicio, O. Tomanec, M. Petr, R. Pocklanova, M.B. Gawande, R.S. Varma, R. Zboril, A.C.S. Appl, Mater. Interfaces 9, 2815 (2017)

36. W.S. Hummers, R.E. Offeman, J. Am. Chem. Soc. 80, 1339 (1958)

37. R. Beams, L.G. Cançado, L. Novotny, J. Phys. Condens. Mat. 27, 083002 (2015)

38. C. Sarkar, S.K. Dolui, RSC Adv. 5, 60763 (2015)

39. K.H. Choi, M. Shokouhimehr, Y.E. Sung, Bull. Korean Chem. Soc. 34, 1477 (2013)

40. K. Zhang, K. Hong, J.M. Suh, T.H. Lee, O. Kwon, M. Shokouhimehr, H.W. Jang, Res. Chem. Intermed. 45, 599 (2019)

41. M. Shokouhimehr, K. Hong, T.H. Lee, C.W. Moon, S.-P. Hong, K. Zhang, J.M. Suh, K.S. Choi, R.S. Varma, H.W. Jang, Green Chem. 40, 3809 (2018)

42. S.M. Rafiaei, A. Kim, M. Shokouhimehr, Nanosci. Nanotech. Lett. 6, 309 (2014)

43. M. Shokouhimehr, K.Y. Shin, J.S. Lee, M.J. Hackett, S.W. Jun, M.H. Oh, J. Jang, T. Hyeon, J. Mater. Chem. A 2, 7593 (2014)

44. K.K. Laali, M. Shokouhimehr, Curr. Org. Chem. 6, 193 (2009)

45. C.W. Moon, J. Park, S.P. Hong, W. Sohn, D.M. Andoshe, M. Shokouhimehr, H.W. Jang, RSC Adv. 8, 18442 (2018)

\section{Submit your manuscript to a SpringerOpen ${ }^{\odot}$ journal and benefit from:}

- Convenient online submission

- Rigorous peer review

- Open access: articles freely available online

- High visibility within the field

- Retaining the copyright to your article

Submit your next manuscript at $\boldsymbol{\nabla}$ springeropen.com 